\title{
Improving Brain Creatine Uptake by Klotho Protein Stimulation: Can Diet Hit the Big Time?
}

\author{
Sergej M. Ostojic* and Dagrun Engeset \\ Department of Nutrition and Public Health, University of Agder, Kristiansand, Norway
}

Keywords: creatine, CT1, brain, Klotho (KL), vitamin D2, curcumin, phosphate-restricted diet, low-calorie highprotein diet

\section{INTRODUCTION}

Creatine plays a pivotal role in cellular bioenergetics, acting as a temporal and spatial energy buffer in cells with high and fluctuating energy requirements (1). Jeopardizing delicate creatine homeostasis can be detrimental to many energy-demanding tissues, including the brain. For instance, cerebral creatine hypometabolism accompanies various neurological conditions, including a number of developmental disorders $(2,3)$, neurodegenerative and cerebrovascular diseases $(4,5)$, and brain cancer $(6)$. A reduced creatine availability in the brain has been thus recognized as an apposite therapeutic target, and supplying exogenous creatine to compensate for a disease-driven shortfall emerged as a first possible approach. However, early success in animal

OPEN ACCESS

Edited by:

Andrew Scholey,

Swinburne University of

Technology, Australia

Reviewed by:

Nafisa M. Jadavii,

Midwestern University, United States

${ }^{*}$ Correspondence:

Sergej M. Ostojic

sergej.ostojic@uia.no

orcid.org/0000-0002-7270-2541

Specialty section:

This article was submitted to

Nutrition and Brain Health,

a section of the journal

Frontiers in Nutrition

Received: 15 October 2021 Accepted: 08 December 2021

Published: 23 December 2021

Citation:

Ostojic SM and Engeset D (2021) Improving Brain Creatine Uptake by Klotho Protein Stimulation: Can Diet

Hit the Big Time?

Front. Nutr. 8:795599.

doi: 10.3389/fnut.2021.795599 models of neurological diseases was not corroborated in human trials, with the use of creatine supplementation proved largely disappointing in clinical studies with a number of symptomatic neurological disorders [for a detailed review, see (7)]. A meager delivery of creatine to the brain could be partly due to a low activity/density of creatine transporter (CT1 or SLC6A8), a transmembrane sodium- and chloride-dependent protein that mediates creatine uptake into the target cells (8). For that reason, the upregulation of CT1 function has been identified as an innovative course of action to facilitate creatine uptake, with several exotic agents and routes were cataloged so far, including glucocorticoid-regulated kinases, mammalian target of rapamycin, ammonia, and Klotho protein (9).

\section{CT1 STIMULATION AND KLOTHO PROTEIN}

Besides other vehicles, Klotho protein (Clotho; HFTC3) is put forward as a possible stimulator of CT1 function that can uplift creatine allocation to the target tissues. This membrane-bound pleiotropic enzyme (also exists in a circulating form) participates in many metabolic pathways, including calcium-phosphate metabolism, nutrient sensing, and remyelination (10). Klotho is highly expressed in neuronal cells of the cerebral cortex, cerebellum, and spinal cord (11). The role of Klotho in high-phosphate energy metabolism modulation was revealed a few years ago when Amilaji et al. (12) found that the co-expression of Klotho protein increases a creatineinduced current in CT1-expressing cells. The authors reported that the current through CT1 was a function of the extracellular creatine levels, with the maximal creatine-induced current was higher in cells expressing CT1 together with Klotho than in cells expressing CT1 alone (29.5 vs. $20.2 \mathrm{nA}$ ). This implies a Klotho-driven upregulation of creatine carriers, presumably by stabilizing the carrier protein in the cell membrane, which likely nominates Klotho protein as a therapeutic proxy to accelerate creatine uptake through CT1. Several methods have been developed lately to raise Klotho levels (13), including a transgenic insertion of the klotho gene, a recombinant Klotho protein administration, or using angiotensin-converting enzyme inhibitor and thiazolidinediones. 


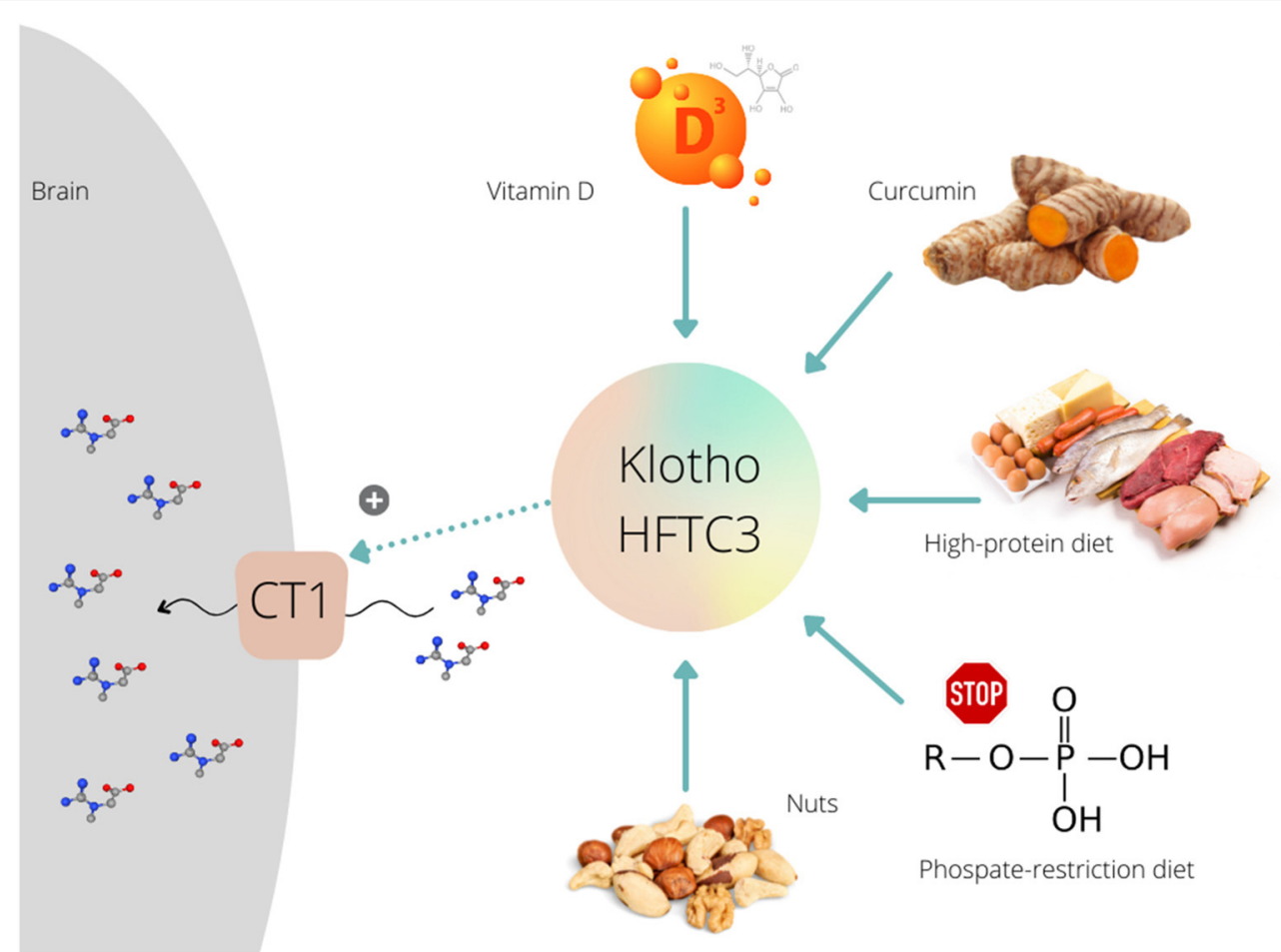

FIGURE 1 | Various dietary interventions upregulate Klotho protein expression/activity that further can stimulate $(+)$ creatine uptake via creatine transporter (CT1) in the brain.

However, nutrition-related interventions might also be capable of enhancing endogenous Klotho production, and perhaps to unlocks CT1 for brain creatine uptake (Figure 1).

\section{KLOTHO MODULATION BY DIET}

Several preclinical studies demonstrated that exposure to vitamin $\mathrm{D}$ could modulate the activity of Klotho protein. A Japanese group (14) treated mice with a vitamin Denriched diet and found increased expression of Klotho; the expression was upregulated and reached maximal levels $8 \mathrm{~h}$ after the administration of 1,25-dihydroxyvitamin D3. Vitamin $\mathrm{D}$ treatment induced a Klotho mRNA hyper-expression in different mouse renal cell lines (15), and in proximal kidney human cells (16). Curcumin, a polyphenol pigment and principal curcuminoid of turmeric (Curcuma longa), is another dietary agent that can upregulate Klotho protein. $\mathrm{Hu}$ et al. (17) demonstrated that curcumin induced Klotho expression in HK2 human proximal tubule epithelial cell line. Recent studies found that the whole-diet interventions are also effective to intensify Klotho function, with a low-calorie high-protein diet increased Klotho levels in rats' brain (18), while a phosphaterestricted diet improved kidney klotho expression in a mouse model of polycystic kidney disease (19). Interestingly, a positive association was found between nuts portion intake and the Klotho plasma levels in middle-aged sedentary adults (20). These preliminary findings call for a set of proof-of-concept studies where supplemental creatine is co-administered with Klotho-stimulating agents while participants are monitored for changes in brain creatine levels. A recent trial confirmed favorable outcomes of a creatine-vitamin D multi-component supplement for functional performance and upregulation of energy metabolism-related kinases in elderly (21). Yet, no biomarkers of Klotho activation and/or creatine uptake by the brain have been evaluated.

\section{CONCLUSION}

Although promising, backing up the Klotho activity to improve creatine delivery to the central nervous system requires robust evidence. Basically, whether the Klotho upregulation induced by a specific dietary intervention is followed by a CT1 triggering and augmented creatine uptake in the brain currently remains unknown. Experimental transport/expression models in neurons would help with addressing CT1-Klotho activation in interventional studies, while clinical trials might include monitoring circulating Klotho as a proxy to Klotho stimulation, along with MR spectroscopy to track down changes in brain creatine levels. Future studies require a careful scrutinization of nutritional strategies utilized in terms of the length of intervention and level of exposure, and adjusted for creatine consumed from food. Additional covariates that can influence the outcome of a given trial also include concomitant pathology 
(such as X-linked creatine transporter deficiency) and nutritional status of participants (e.g., vitamin D deficiency, creatine-free diet), along with other factors (including age, physical exercise, and level of education) that could play important role on CT1 and Klotho protein function and/or creatine homeostasis in the brain. For instance, animal studies suggest sex differences in Klotho protein expression, with the levels were higher in the male mice than in the female mice (22). Klotho function could also be affected by HMG-CoA reductase inhibitors (23), uremiarelated compounds (24), or demethylation agents (25). Therefore, accounting for various endogenous and exogenous modulators of Klotho protein should be required for upcoming nutritional

\section{REFERENCES}

1. Wallimann T, Tokarska-Schlattner M, Schlattner U. The creatine kinase system and pleiotropic effects of creatine. Amino Acids. (2011) 40:127196. doi: 10.1007/s00726-011-0877-3

2. Fons C, Campistol J. Creatine defects and central nervous system. Semin Pediatr Neurol. (2016) 23:285-9. doi: 10.1016/j.spen.2016.11.003

3. Edmondson DA, Xia P, McNally Keehn R, Dydak U, Keehn B, A. magnetic resonance spectroscopy study of superior visual search abilities in children with autism spectrum disorder. Autism Res. (2020) 13:55062. doi: 10.1002/aur.2258

4. van den Bogaard SJ, Dumas EM, Teeuwisse WM, Kan HE, Webb A, Roos RA, et al. Exploratory 7-Tesla magnetic resonance spectroscopy in Huntington's disease provides in vivo evidence for impaired energy metabolism. J Neurol. (2011) 258:2230-9. doi: 10.1007/s00415-011-6099-5

5. Lin AQ, Shou JX Li XY, Ma L, Zhu XH. Metabolic changes in acute cerebral infarction: Findings from proton magnetic resonance spectroscopic imaging. Exp Ther Med. (2014) 7:451-5. doi: 10.3892/etm.2013.1418

6. Kinoshita Y, Yokota A. Absolute concentrations of metabolites in human brain tumors using in vitro proton magnetic resonance spectroscopy. NMR Biomed. (1997) 10:212. doi: 10.1002/(sici)1099-1492(199701)10:1<2::aid-nbm442>3.0.co;2-n

7. Bender A, Klopstock T. Creatine for neuroprotection in neurodegenerative disease: end of story? Amino Acids. (2016) 48:1929-40. doi: 10.1007/s00726-015-2165-0

8. Ohtsuki S, Tachikawa M, Takanaga H, Shimizu H, Watanabe M, Hosoya K, et al. The blood-brain barrier creatine transporter is a major pathway for supplying creatine to the brain. J Cereb Blood Flow Metab. (2002) 22:132735. doi: 10.1097/01.WCB.0000033966.83623.7D

9. Ostojic SM. Modulation of CT1 function: from klotho protein to ammonia and beyond. Front Nutr. (2021) 8:660021. doi: 10.3389/fnut.2021.660021

10. Torbus-Paluszczak M, Bartman W, Adamczyk-Sowa M. Klotho protein in neurodegenerative disorders. Neurol Sci. (2018) 39:1677-82. doi: 10.1007/s10072-018-3496-x

11. Lim K, Groen A, Molostvov G, Lu T, Lilley KS, Snead D, et al. $\alpha$-Klotho expression in human tissues. J Clin Endocrinol Metab. (2015) 100:E130818. doi: $10.1210 /$ jc. $2015-1800$

12. Almilaji A, Sopjani M, Elvira B, Borras J, Dërmaku-Sopjani M, Munoz C, et al. Upregulation of the creatine transporter Slc6A8 by Klotho. Kidney Blood Press Res. (2014) 39:516-25. doi: 10.1159/000368462

13. Pastor J, Moe OW. Treating systemic Klotho deficiency. Am J Nephrol. (2019) 49:410-2. doi: 10.1159/00049 9864

14. Tsujikawa H, Kurotaki Y, Fujimori T, Fukuda K, Nabeshima Y. Klotho, a gene related to a syndrome resembling human premature aging, functions in a negative regulatory circuit of vitamin D endocrine system. Mol Endocrinol. (2003) 17:2393-403. doi: 10.1210/me.2003-0048

15. Barthel TK, Mathern DR, Whitfield GK, Haussler CA, Hopper HA 4th, Hsieh JC, et al. 1,25-Dihydroxyvitamin D3/VDR-mediated induction of FGF23 as well as transcriptional control of other bone anabolic and catabolic genes that trials addressing brain creatine uptake through this pathway. The new knowledge about a possible diet-induced stimulation of Klotho protein opens an exciting opportunity for exploring various nutritional strategies aimed to potentiate cerebral uptake of creatine. This could perhaps bring forth a solution to the many who suffer from acquired or inherited creatine deficits.

\section{AUTHOR CONTRIBUTIONS}

SO designed and wrote the manuscript and has primary responsibility for the final content. All authors read, revised, and approved the final version of the manuscript. orchestrate the regulation of phosphate and calcium mineral metabolism. $J$ Steroid Biochem Mol Biol. (2007) 103:381-8. doi: 10.1016/j.jsbmb.2006.12.054

16. Haussler MR, Haussler CA, Whitfield GK, Hsieh JC, Thompson PD, Barthel TK, et al. The nuclear vitamin D receptor controls the expression of genes encoding factors which feed the "Fountain of Youth" to mediate healthful aging. J Steroid Biochem Mol Biol. (2010) 121:8897. doi: $10.1016 /$ j.jsbmb.2010.03.019

17. Hu Y, Mou L, Yang F, Tu H, Lin W. Curcumin attenuates cyclosporine Ainduced renal fibrosis by inhibiting hypermethylation of the klotho promoter. Mol Med Rep. (2016) 14:3229-36. doi: 10.3892/mmr.2016.5601

18. Shafie A, Rahimi AM, Ahmadi I, Nabavizadeh F, Ranjbaran M, Ashabi G. High-protein and low-calorie diets improved the anti-aging Klotho protein in the rats' brain: the toxic role of high-fat diet. Nutr Metab. (2020) 17:86. doi: 10.1186/s12986-020-00508-1

19. Omede F, Zhang S, Johnson C, Daniel E, Zhang Y, Fields TA, et al. Dietary phosphate restriction attenuates polycystic kidney disease in mice. Am J Physiol Renal Physiol. (2020) 318:F35-42. doi: 10.1152/ajprenal.00282.2019

20. Jurado-Fasoli L, Amaro-Gahete FJ, De-la-O A, Martinez-Tellez B, Ruiz JR, Gutiérrez Á, et al. Adherence to the Mediterranean diet, dietary factors, and S-Klotho plasma levels in sedentary middle-aged adults. Exp Gerontol. (2019) 119:25-32. doi: 10.1016/j.exger.2019.01.019

21. Evans M, Guthrie N, Pezzullo J, Sanli T, Fielding RA, Bellamine A. Efficacy of a novel formulation of L-Carnitine, creatine, and leucine on lean body mass and functional muscle strength in healthy older adults: a randomized, double-blind placebo-controlled study. Nutr Metab. (2017) 14:7. doi: 10.1186/s12986-016-0158-y

22. de Mello NP, Andreotti DZ, Orellana AM, Scavone C, Kawamoto EM. Inverse sex-based expression profiles of PTEN and Klotho in mice. Sci Rep. (2020) 10:20189. doi: 10.1038/s41598-020-77217-5

23. Narumiya H, Sasaki S, Kuwahara N, Irie H, Kusaba T, Kameyama H, et al. HMG-CoA reductase inhibitors up-regulate anti-aging klotho mRNA via RhoA inactivation in IMCD3 cells. Cardiovasc Res. (2004) 64:3316. doi: 10.1016/j.cardiores.2004.07.011

24. Sun CY, Chang SC, Wu MS. Suppression of Klotho expression by proteinbound uremic toxins is associated with increased DNA methyltransferase expression and DNA hypermethylation. Kidney Int. (2012) 81:64050. doi: 10.1038/ki.2011.445

25. Jung $\mathrm{D}, \mathrm{Xu} \mathrm{Y}$, Sun $\mathrm{Z}$. Induction of anti-aging gene klotho with a small chemical compound that demethylates $\mathrm{CPG}$ islands. Oncotarget. (2017) 8:46745-55. doi: 10.18632/oncotarget.18608

Conflict of Interest: SO serves as a member of the Scientific Advisory Board on creatine in health and medicine (AlzChem LLC.). SO owns patent "Sports Supplements Based on Liquid Creatine" at European Patent Office (WO2019150323 A1), and active patent application "Synergistic Creatine" at UK Intellectual Property Office (GB2012773.4). SO has served as a speaker at Abbott Nutrition, a consultant of Allied Beverages Adriatic and IMLEK, and has received research funding related to creatine and/or guanidinoacetic acid from the Serbian Ministry of Education, Science, and Technological Development, Provincial Secretariat for Higher Education and Scientific Research, AlzChem GmbH, 
KW Pfannenschmidt GmbH, Monster Beverage Corporation, and ThermoLife International LLC. SO does not own stocks and shares in any organization.

The remaining author declares that the research was conducted in the absence of any commercial or financial relationships that could be construed as a potential conflict of interest.

Publisher's Note: All claims expressed in this article are solely those of the authors and do not necessarily represent those of their affiliated organizations, or those of the publisher, the editors and the reviewers. Any product that may be evaluated in this article, or claim that may be made by its manufacturer, is not guaranteed or endorsed by the publisher.

Copyright (๑) 2021 Ostojic and Engeset. This is an open-access article distributed under the terms of the Creative Commons Attribution License (CC BY). The use, distribution or reproduction in other forums is permitted, provided the original author(s) and the copyright owner(s) are credited and that the original publication in this journal is cited, in accordance with accepted academic practice. No use, distribution or reproduction is permitted which does not comply with these terms. 